REVIEW

\title{
Drotrecogin alfa (activated): a novel therapeutic strategy for severe sepsis
}

\section{S M Pastores}

Postgrad Med J 2003;79:5-10

Recent studies have highlighted the close link between activation of the coagulation system and the inflammatory response in the pathophysiology of severe sepsis. The protein $C$ anticoagulant pathway plays an integral part in modulating the coagulation and inflammatory responses to infection. In patients with sepsis, endogenous protein $C$ levels are decreased, shifting the balance toward greater systemic inflammation, coagulation, and cell death. On the basis of a single large randomised phase 3 trial, drotrecogin alfa (activated), a recombinant form of human activated protein C, was recently approved for the treatment of adult patients with severe sepsis and a high risk of death. Since its approval, several questions have been raised regarding the appropriate use of this agent. Given the increased risk of serious bleeding and the high cost of treatment, drotrecogin alfa (activated) should be reserved at this time for the most acutely ill patients with severe sepsis who meet the criteria that were used in the phase 3 trial.

Correspondence and
reprint requests to:
Dr Stephen M Pastores,
Department of
Anesthesiology and Critical
Care Medicine, Memorial
Sloan-Kettering Cancer
Center, 1275 York Avenue
M-210 New York, NY
10021, USA;
pastores@mskcc.org
Submitted
25 June 2002
Accepted
14 October 2002

D rotrecogin alfa (activated) (Xigris, Eli Lilly, Indianapolis, USA), formerly referred to as recombinant human activated protein $\mathrm{C}$, is a glycoprotein analogue of endogenous protein $\mathrm{C}$ synthesised and secreted by genetically engineered human cells. ${ }^{12}$ Activated protein $\mathrm{C}$ is an important modulator of the coagulation and inflammation associated with severe sepsis. In sepsis patients, protein $\mathrm{C}$ is depleted and the ability to produce endogenous activated protein $\mathrm{C}$ is impaired, shifting the balance toward greater systemic inflammation, coagulation, and cell death. ${ }^{3}$ Drotrecogin alfa (activated) was approved by the United States Food and Drug Administration in November 2001 for the treatment, in combination with standard therapy, of critically ill adult patients with severe sepsis and a high risk of death. ${ }^{4}$

\section{CLINICAL FEATURES OF SEVERE SEPSIS}

Severe sepsis, defined as sepsis associated with acute organ dysfunction, results from a generalised inflammatory and procoagulant response to infection..$^{5-7}$ The incidence of sepsis in the United States has been estimated at approximately 750000 cases per year with annual costs of nearly $\$ 17$ billion. ${ }^{8}$ Despite advances in supportive care, severe sepsis carries a high mortality rate, ranging from $30 \%$ to $50 \% .^{9-12}$

The severe sepsis syndrome is characterised by circulatory shock and development of multiorgan dysfunction that can lead to death. ${ }^{13}$ Standard therapy consists of eradication of the source of infection, administration of antimicrobial therapy, and cardiovascular support. ${ }^{14}$ Early and aggressive haemodynamic optimisation with defined resuscitation endpoints appears to influence patient outcomes in severe sepsis. Rivers and colleagues recently showed in a study of patients who presented to the emergency department with severe sepsis and septic shock, that early goal directed therapy consisting of fluid resuscitation, vasoactive drugs, and red cell transfusions, can result in substantial reduction in mortality rates when compared with standard therapy alone. $^{15}$

For over 25 years, clinical trials with adjunctive agents to treat severe sepsis focused largely on inhibition of the inflammatory response, including use of glucocorticoids, neutralising antibodies against endotoxin, and specific inhibitors of proinflammatory mediators. ${ }^{16-18}$ Unfortunately, these anti-inflammatory therapies failed to show any significant improvement in outcome, perhaps due to non-specificity of the agents tested, limitations in study design and patient selection, and to the lack of recognition of the importance of the coagulation system in sepsis. ${ }^{19} 20$

In the past 10 years, there has been increased recognition of the tight interplay and coupling of inflammation, microvascular coagulation, and endothelial cell injury in the pathophysiology of severe sepsis. ${ }^{3621}$ These findings have led to clinical trials investigating agents with both anticoagulant and anti-inflammatory effects as adjunctive therapies in severe sepsis, including activated protein $\mathrm{C}$, tissue factor pathway inhibitor (TFPI), and antithrombin III. ${ }^{7922-24}$ Of these three agents, only activated protein $\mathrm{C}$ was demonstrated to have a survival benefit. To better understand the role of activated protein $\mathrm{C}$ in the pathophysiology of sepsis and the rationale for its use in the treatment of this disorder, it is necessary to review the protein $\mathrm{C}$ anticoagulant pathway and its relationship to the sepsis syndrome.

Abbreviations: APACHE II, Acute Physiology and Chronic Health Evaluation II (score); HSCT,

haematopoietic stem cell transplantation; PAI-1, plasminogen activator inhibitor- 1; TFPI; tissue factor pathway inhibitor; TNF- $\alpha$, tumour necrosis factor- $\alpha$ 


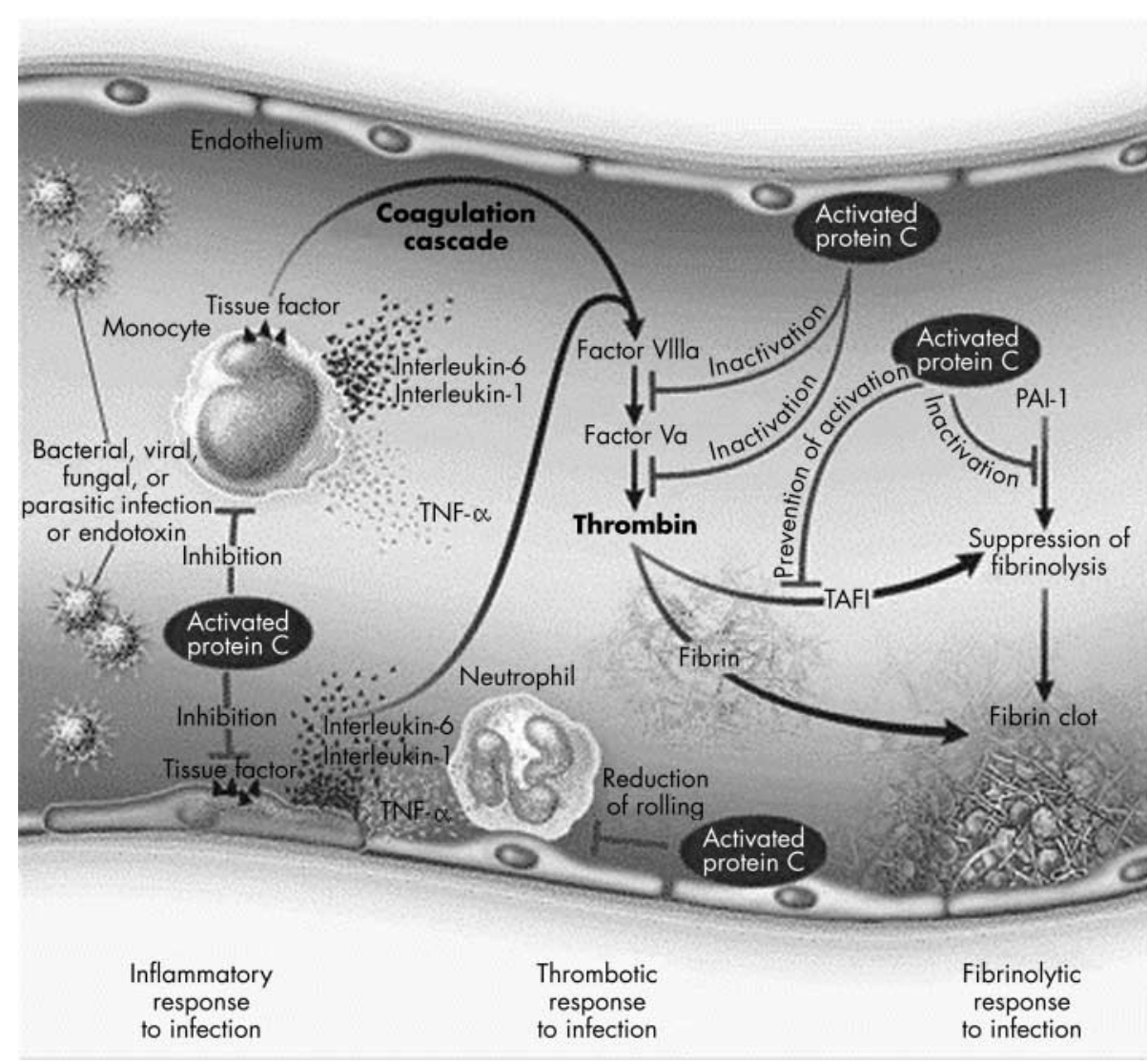

Figure 1 Mechanisms of action of activated protein C. Severe sepsis is characterised by inflammatory, prothrombotic, and impaired fibrinolytic responses. Activated protein $C$ exerts both anti-inflammatory and anticoagulant effects at different levels during the systemic response to infection. The anti-inflammatory actions include inhibition of the production of tumour necrosis factor- $\alpha$ (TNF- $\alpha$ ) and interleukin- 6 by monocytes and decreased expression of adhesion molecules on endothelial cells. In addition, activated protein $C$ inhibits factors Va and VIlla resulting in decreased thrombin generation and increases the fibrinolytic response by reducing the levels of plasminogen activator inhibitor-1 (PAI-1) (TAFI, thrombin activator fibrinolysis inhibitor). Adapted from Bernard et aP with the permission of the publisher.

\section{PROTEIN C ANTICOAGULANT PATHWAY AND SEVERE SEPSIS}

The association between the activation of the coagulation system and severe sepsis has been known for over 30 years. ${ }^{25}$ During sepsis, the release of microbial toxins and inflammatory cytokines, including tumour necrosis factor- $\alpha$ (TNF- $\alpha$ ), interleukin- $1 \beta$, and interleukin-6 from tissue macrophages into the systemic circulation set off a cascade of events that results in widespread inflammation, endothelial injury, and microvascular thrombosis (fig 1). ${ }^{1326}$ Among the earliest events that occur during the inflammatory response to infection is the adhesion of leucocytes to endothelial cells that is promoted by the proinflammatory cytokines through the up-regulation of adhesion molecules, such as E-selectin and P-selectin. ${ }^{27}$ These adhesion molecules allow activated neutrophils to release various proteases and other proinflammatory cytokines that contribute to impaired blood flow and oxidant injury to blood vessels. ${ }^{327}$

In addition to initiating the inflammatory cascade, microbial toxins and inflammatory cytokines generate a procoagulant environment through several mechanisms, including the activation of the extrinsic coagulation pathway through the expression of tissue factor from injured endothelial cells and activated monocytes. ${ }^{28}{ }^{29}$ Tissue factor is the key mediator of coagulation activation in patients with sepsis. Tissue factor binds to activated factor VII to form the tissue factor/factor VIIa complex, which in turn, activates factor X. Activated factor $\mathrm{X}$ along with activated factor $\mathrm{V}(\mathrm{Va})$ converts prothrombin to thrombin, which cleaves fibrinogen to generate fibrin monomers, which then polymerise to form the fibrin clot. The importance of tissue factor in coagulation activation in sepsis was confirmed in studies of healthy volunteers and nonhuman primates exposed to endotoxin where inhibition of tissue factor by either TFPI or antitissue factor monoclonal antibody prevented thrombin generation and fibrin clot formation. $^{30}$
Conversely, proinflammatory events may be induced by components of the coagulation system. ${ }^{26}{ }^{31-35}$ For example, thrombin has been shown to induce direct proinflammatory responses in endothelial cells and macrophages. ${ }^{36}{ }^{37}$ Similarly, tissue factor/factor VIIa complex can enhance production of reactive oxygen species and expression of major histocompatibility class II and cell adhesion receptors in macrophages. ${ }^{38}$ Thus, there are several synergistic pathways by which inflammatory and procoagulant mechanisms can initiate and perpetuate microvascular thrombosis, tissue hypoperfusion, and organ dysfunction in patients with sepsis. ${ }^{20}$

Abnormalities in coagulation and fibrinolysis are commonly observed in patients with sepsis and have been associated with decreased survival. ${ }^{34}{ }^{39-43}$ These include reductions in all major physiological anticoagulants-antithrombin III, protein $\mathrm{C}$, and TFPI associated with increases in plasminogen activator inhibitor-1 (PAI-1) and thrombin activator fibrinolysis inhibitor, which both inhibit fibrinolysis. Systemic formation of fibrin results from increased generation of thrombin, suppression of physiological anticoagulant mechanisms, and impaired fibrinolysis. ${ }^{28}{ }^{43}$ The widespread activation of coagulation resulting in the intravascular deposition of fibrin and ultimately thrombotic occlusion of small and medium size vessels, commonly referred to as disseminated intravascular coagulation, has been implicated in the development of sepsis induced multiorgan failure. ${ }^{28}$

Under normal physiological conditions, the protein C pathway plays a critical part in the maintenance of haemostasis and modulation of inflammation. ${ }^{34}$ Protein C is a vitamin Kdependent glycoprotein synthesised by the liver that consists of a 155 amino acid peptide (light chain) and a 304 amino acid peptide (heavy chain), joined by a single disulphide bridge. ${ }^{45}$ The light chain contains gamma carboxyglutamate residues in its $\mathrm{N}$-terminal region, which are required for intracellular processing and for calcium-dependent binding to negatively charged membranes. The heavy chain contains the serine protease domain. It is noteworthy that endogenous protein $\mathrm{C}$ 
undergoes several complex post-translational modifications which provides a source of heterogeneity in the molecule.

Protein $\mathrm{C}$ circulates in the blood as an inactive zymogen. In the presence of thrombin, protein $\mathrm{C}$ binds to two receptors on the endothelial surface, thrombomodulin and the endothelial protein $\mathrm{C}$ receptor, and becomes converted into activated protein C. Activated protein $\mathrm{C}$ with protein $\mathrm{S}$ serving as an essential cofactor, inactivates factors Va and VIIIa, thereby inhibiting thrombin generation. In addition, activated protein $C$ stimulates fibrinolysis by decreasing the concentration of PAI-1. Finally, activated protein $\mathrm{C}$ has direct antiinflammatory effects as demonstrated by its ability to inhibit both the production of TNF- $\alpha$ and interleukin- 1 by monocytes and the expression of E-selectin on endothelial cells, thereby inhibiting leucocyte attachment to the endothelium (fig 1). ${ }^{34}$ Activated protein C may also directly modulate cell signalling and endothelial cell gene expression patterns. ${ }^{46}$ Molecular studies have revealed that activated protein $C$ inhibits the TNF-mediated expression of cell adhesion molecules on endothelial cell surface by down-regulation of the transcription factor NF-KB. ${ }^{47}$ Activated protein $\mathrm{C}$ has also been shown to enhance the expression of several apoptotic genes including the Bcl-2 homologue protein and inhibitor of apoptosis-1, thus preventing apoptosis (programmed cell death). ${ }^{46-48}$ Taken together, these observations indicate that activated protein $\mathrm{C}$, in addition to its antithrombotic and profibrinolytic properties, plays a crucial part in maintaining the balance of anti-inflammatory and antiapoptotic systems in response to injury. ${ }^{47}$

The conversion of protein $\mathrm{C}$ to activated protein $\mathrm{C}$ is impaired during sepsis as a result of the down-regulation of thrombomodulin and the endothelial cell protein $\mathrm{C}$ receptor by proinflammatory cytokines. ${ }^{34}{ }^{49}$ Reduced levels of protein $\mathrm{C}$ have been correlated with increased morbidity and mortality in patients with severe sepsis and septic shock. ${ }^{40-43} 50$

Replacement therapy with protein C concentrate has been shown to prevent coagulopathy and improve survival in animal models of Gram negative sepsis, ${ }^{51}$ and in humans with severe meningococcaemia where dysfunction of the protein $C$ activation pathway is deemed critical to the development of disseminated intravascular coagulation and purpura fulminans. ${ }^{49}{ }^{52-58}$ Since protein $\mathrm{C}$ activation is impaired in severe sepsis due to the decreased expression of thrombomodulin and endothelial protein $\mathrm{C}$ receptor, the administration of activated protein C may offer a theoretical advantage over unactivated protein C. On the basis of promising preclinical data, clinical trials designed to determine the safety and efficacy of drotrecogin alfa (activated) in severe sepsis were initiated.

\section{PHARMACOLOGY AND PHARMACOKINETICS}

Drotrecogin alfa (activated) is a recombinant form of endogenous activated protein $\mathrm{C}$ and is expressed in the human kidney cell line $293 . .^{59}$ The drug has a molecular weight of approximately 55 kilodaltons and similar to endogenous protein $C$ consists of a heavy chain and a light chain linked by a disulphide bond. Drotrecogin alfa (activated) and endogenous protein $\mathrm{C}$ have the same sites of glycosylation and differ only in specific glycosyl residues. Although their amino acid structure is similar, differences exist due to the complex posttranslational modifications that occur with endogenous protein $\mathrm{C}$.

The pharmacological effects of drotrecogin alfa (activated) are related to its antithrombotic, profibrinolytic, and antiinflammatory properties. ${ }^{40}$ In patients with severe sepsis, steady state plasma concentrations are reached within two hours after infusions of $12 \mu \mathrm{g} / \mathrm{kg} /$ hour to $30 \mu \mathrm{g} / \mathrm{kg} / \mathrm{hour}$ of drotrecogin alfa (activated) are begun. ${ }^{22}$ The drug is inactivated by endogenous plasma protease inhibitors. In the majority of patients, plasma levels of the drug decrease to
Box 1: Clinical settings and criteria for use of drotrecogin alfa (activated)

- Adult and paediatric patients with meningococcal sepsis and purpura fulminans.

- Adult patients (age >18 years) with documented source of infection or a highly suspected source of infection, at least three of the systemic inflammatory response criteria (fever or hypothermia, tachycardia, tachypnoea, leucocytosis, or leucopenia), and evidence of acute end organ dysfunction including shock, severe hypoxaemia, oliguria, or acidosis.

- High likelihood of death from severe sepsis as estimated by APACHE II score of 25 or greater.

- Absence of an increased risk of bleeding including severe thrombocytopenia (platelet count $<30 \times 10^{9} / 1$ ), prothrombin time/international normalised ratio $>3.0$, concurrent therapeutic heparin ( $\geqslant 15$ units $/ \mathrm{kg} /$ hour), recent (within six weeks) gastrointestinal bleeding, chronic liver disease, organ transplant recipients, and conditions listed in box 2 .

\section{Box 2: Contraindications to administration of} drotrecogin alfa (activated)

- Active internal bleeding.

- Recent haemorrhagic stroke (within three months)

- Severe head trauma (within two months).

- Recent intracranial or intraspinal surgery (within two months).

- Intracranial neoplasm or mass lesion.

- Evidence of cerebral herniation.

- Presence of an epidural catheter.

- Trauma with an increased risk of life threatening bleeding

- Hypersensitivity to drotrecogin alfa (activated) or any component of the formulation.

undetectable levels within two hours after cessation of the infusion. In the phase 3 trial, the mean clearance of the drug was approximately $40 \mathrm{l} /$ hour. $^{7}$ The plasma clearance of drotrecogin alfa (activated) in patients with severe sepsis is approximately $50 \%$ higher than that in healthy subjects, ${ }^{60}$ and is most likely due to the increased levels of endogenous serine protease inhibitors that occurs in septic patients.

In the phase 3 trial, small differences were detected in the plasma clearance of drotrecogin alfa (activated) with regard to age, gender, and the presence of hepatic or renal dysfunction; therefore, dose adjustment is not required based on these factors. ${ }^{460}$ The clearance rate of drotrecogin alfa (activated) in septic patients with underlying renal and liver failure is unknown because these patients were excluded from the phase 2 and 3 trials.

\section{INDICATIONS FOR DROTRECOGIN ALFA (ACTIVATED)}

Drotrecogin alfa (activated) is indicated for the treatment of highly selected adult patients with severe sepsis and evidence of organ failure who have a high risk of death as measured by a scoring system based on their general health and the severity of their illness (Acute Physiology and Chronic Health Evaluation II [APACHE II] score of 25 or greater) (box 1) and in whom there are no signs of active bleeding or conditions that predispose to increased bleeding (box 2) ${ }^{61}$ The drug is administered as a continuous intravenous infusion at a rate of $24 \mu \mathrm{g} / \mathrm{kg} /$ hour for 96 hours. All patients receiving the drug should be monitored for signs and symptoms of bleeding and for levels of haemoglobin, platelet count, and prothrombin time/international normalised ratio during infusion. Unlike heparin, the administration of drotrecogin alfa (activated) may interfere with the assay used to measure activated partial 
thromboplastin time; therefore, the activated partial thromboplastin time cannot be used to monitor treatment with this agent.

It is recommended that drug infusion be discontinued two hours before undergoing an invasive surgical procedure or procedures known to be associated with an increased risk of bleeding. ${ }^{40}$ The drug may be resumed once adequate haemostasis has been achieved but no earlier than 12 hours after major surgery or highly invasive procedures or two hours after uncomplicated less invasive procedures.

\section{CLINICAL TRIALS OF DROTRECOGIN ALFA (ACTIVATED)}

Thirteen phase 1 studies were conducted with drotrecogin alfa (activated), including eight studies in 110 healthy volunteers, three in 30 patients with end stage renal disease, one in nine patients with heterozygous protein $\mathrm{C}$ deficiency, and one study of 35 adult and paediatric patients with purpura fulminans. These phase 1 studies demonstrated that drotrecogin alfa (activated) was safe and well tolerated with predictable pharmacokinetic and pharmacodynamic indices.

A double blind, randomised, placebo controlled, multiinstitutional phase 2 study involving 131 adult patients with severe sepsis evaluated a range of doses $(12,18,24$, or 30 $\mu \mathrm{g} / \mathrm{kg} /$ hour) of drotrecogin alfa (activated) administered as continuous intravenous infusions for either 48 hours or 96 hours. ${ }^{22}$ Drotrecogin alfa (activated) was safe and well tolerated and demonstrated a dose dependent reduction in D-dimer (a marker of coagulation activation) and interleukin-6 levels relative to placebo. Clinically significant bleeding events occurred in only $3 \%$ of the patients, including no occurrence of intracranial haemorrhage. Mortality rates were similar in drotrecogin alfa (activated) and placebo groups, but the study was underpowered to detect a mortality benefit. Patients treated with the $24 \mu \mathrm{g} / \mathrm{kg} / \mathrm{hour}$ infusion for 96 hours demonstrated significantly greater percent decreases in D-dimer levels than placebo and low dose drotrecogin alfa (activated) treated patients, thus this dose was chosen for the phase 3 trial.

The phase 3 trial that resulted in the approval of drotrecogin alfa (activated) was a randomised, double blind international study involving 1690 adult patients with severe sepsis conducted from July 1998 through June 2000. ${ }^{7}$ Entry criteria included the presence of three or more signs of systemic inflammation (fever or hypothermia, tachycardia, tachypnoea and leucocytosis, or leucopenia) and at least one sepsis induced organ dysfunction present for no longer than 24 hours. ${ }^{5}$ Approximately $75 \%$ of the patients were in shock and/or receiving mechanical ventilation at the time of initial treatment. Approximately $90 \%$ of the patients in both the drotrecogin alfa (activated) group and the placebo group received appropriate antibiotics within 24 hours of the onset of severe sepsis. ${ }^{62}$ Patients received a 96 hour infusion of 24 $\mu \mathrm{g} / \mathrm{kg} /$ hour of drotrecogin alfa (activated) or placebo, started within 48 hours of organ dysfunction. Patients with active bleeding or conditions that predisposed to an increased risk of bleeding (for example, platelet count $<30 \times 10^{9} / 1$, need for full therapeutic anticoagulation, recent stroke, intracranial or spinal surgery, and severe head trauma) and patients with significant comorbid illnesses (for example, chronic renal failure requiring dialysis, liver cirrhosis, and immunocompromised patients) were excluded. Protein C deficiency was present in approximately $90 \%$ of the patients in whom levels were measured. Patients who received drotrecogin alfa (activated) had a significantly lower 28 day mortality rate compared with patients who received placebo (25\% v 31\%, $\mathrm{p}=0.005$ ). The $6 \%$ absolute reduction in mortality represented a reduction in the relative risk of death of $19.4 \%(95 \%$ confidence interval 6.6 to 30.5 ). Patients with the highest risk of dying from sepsis at study entry (as determined by an
APACHE II score >25) who received drotrecogin alfa (activated) had a higher survival rate than similarly treated patients with a lower risk of death. Decreases in serum levels of interleukin-6 were observed in the drotrecogin alfa (activated) treated patients consistent with the antiinflammatory effect of activated protein C. There was also a greater reduction in plasma $\mathrm{D}$-dimer levels in patients who received drotrecogin alfa (activated) as compared with the patients who received placebo.

\section{ADVERSE EFFECTS}

The adverse effects of drotrecogin alfa (activated) are related to the anticoagulant activity of the drug. ${ }^{72}$ Bleeding is the major toxicity of drotrecogin alfa (activated). In the phase 3 study, serious bleeding events (defined as any life threatening bleeding, intracranial haemorrhage, or bleeding requiring more than three units of packed red cells/day on two consecutive days), including four fatal haemorrhages, occurred in 30 patients (3.5\%) treated with drotrecogin alfa (activated), and in 17 patients $(2 \%)$, including one fatal haemorrhage, with placebo. ${ }^{7}$ Gastrointestinal and intra-abdominal bleeding were the most common, and most serious bleeding occurred during the infusion. Bleeding was not increased in patients who also received subcutaneous heparin for the prevention of deep vein thrombosis. As of September 2002, drotrecogin alfa (activated) has been administered to 2786 patients (adult and paediatric) with severe sepsis in controlled and open label studies. ${ }^{63}$ Intracranial haemorrhage has occurred in 13 of the 2786 patients accounting for a current rate of $0.5 \% \cdot{ }^{63}$ Approximately $70 \%$ of the intracranial haemorrhages occurred in patients with platelet counts $<30 \times 10^{9} /$ l, meningitis, or both.

The contraindications to drotrecogin alfa (activated) are shown in box 2. Treatment of haemorrhagic complications during infusion of drotrecogin alfa (activated) is supportive, including immediate discontinuation of the infusion and administration of blood products. There is no known antidote. ${ }^{59} 60$

There has been minimal immunogenicity reported with drotrecogin alfa (activated). ${ }^{722}$ One patient in the phase 2 study developed antibodies to drotrecogin alfa (activated) without clinical sequelae. Similarly, one patient in the phase 3 study who developed antibodies to the drug had superficial and deep venous thrombi during the study and died of multiorgan failure 36 days after treatment. It is important to note that the true incidence of antibody formation in patients receiving drotrecogin alfa (activated) has not been adequately determined because of several problems related to the sensitivity, specificity, background (signal to noise ratio), and quantification of the antibody detection assays used in the phase 2 and 3 trials. ${ }^{4}$

There have been no formal drug interaction studies with drotrecogin alfa (activated) conducted to date. Close monitoring should be undertaken in patients on drotrecogin alfa (activated) therapy who may also be receiving agents that affect the coagulation system including unfractionated or low molecular weight heparins, antiplatelet agents, non-steroidal anti-inflammatory drugs, and warfarin. In the phase 3 study, approximately two thirds of the patients received prophylactic low dose heparin and patients receiving up to $650 \mathrm{mg} /$ day of acetylsalicylic acid were also enrolled.?

\section{UNANSWERED QUESTIONS}

The phase 3 study of drotrecogin alfa (activated) for severe sepsis had several limitations, including the enrollment of a highly selected patient population with no increased risk of bleeding and the lack of information on outcome measures other than 28 day mortality, such as survival in the hospital, time on the ventilator, and length of stay in the intensive care unit. Since its approval, many questions have been raised regarding the appropriate use of drotrecogin alfa (activated). 
How will the high risk of death be determined to justify the administration of drotrecogin alfa (activated) in septic patients? General prognostic scoring systems such as the APACHE II are infrequently used by intensive care practitioners; thus, there is a huge problem with operationalising the use of APACHE II in clinical practice. Clearly septic patients with two or more organ failures and/or requiring high dose vasopressor support identify a high risk group that may benefit from the drug, regardless of their APACHE II scores.

Can other groups of patients, such as those with active haematological malignancy or those undergoing solid organ or haematopoietic stem cell transplantation (HSCT) who develop severe sepsis, benefit from drotrecogin alfa (activated) despite the associated increased risks of bleeding related to thrombocytopenia and/or coagulopathy? Interestingly, patients undergoing HSCT develop a hypercoagulable state characterised by deficiencies in circulating protein C and antithrombin III and increases in interleukin-6 levels, both of which are associated with development of organ dysfunction and a negative outcome. ${ }^{64}{ }^{65}$ It is possible that the low levels of activated protein $C$ and increased levels of interleukin- 6 in patients undergoing HSCT predispose these patients to complications of severe sepsis and multiorgan failure; thus, treatment with drotrecogin alfa (activated) may provide potential clinical benefit. However, it is not known whether drotrecogin alfa (activated) will adversely affect the transplant outcome.

Would a longer infusion period (for example, seven days) be even more beneficial in patients with severe sepsis who continue to demonstrate circulatory shock or signs of organ hypoperfusion? In the phase 3 trial, D-dimer levels remained elevated after the 96 hour infusion of drotrecogin alfa (activated) suggesting a longer infusion period may be warranted for selected patients.

Approximately $30 \%$ of the patients enrolled in the phase 3 study received concomitant corticosteroids. ${ }^{4}$ An analysis of this subgroup revealed that the mortality rate was lower in patients who received drotrecogin alfa (activated) than placebo whether or not the patients received corticosteroids at baseline or during the infusion period. In light of a recent multicentre study that showed improved outcomes in patients with septic shock treated with low dose corticosteroids, ${ }^{66}$ further studies will be necessary to evaluate the interaction between drotrecogin alfa (activated) and corticosteroids in severe sepsis.

Drotrecogin alfa (activated) will likely be combined in selected patients with other novel antisepsis agents that are currently in development or undergoing phase 2 or 3 trials such as secretory phospholipase A2 inhibitor, platelet activating factor acetylhydrolase, and pyridoxylated haemoglobin polyoxyethylene. ${ }^{67}$ Without the knowledge of how these agents may interact when administered in combination, how will investigators differentiate between the additive versus antagonistic effects from such combinations?

Finally, given the increased risk of serious bleeding and the high cost of treatment (approximately $\$ 8000$ for a 96 hour infusion in a $70 \mathrm{~kg}$ adult) ${ }^{68}$ clearly drotrecogin alfa (activated) should be reserved at this time for the most acutely ill patients with severe sepsis who meet the criteria that were used in the phase 3 trial. The decision to use this agent in patient subgroups that were not represented in the phase 3 trial should be undertaken on an individualised basis, meticulously balancing the potential for clinical benefit against the increased risk of bleeding. ${ }^{67}$

Padkin et al estimated that approximately 10000 patients a year might be eligible to receive drotrecogin alfa (activated) in the United Kingdom. ${ }^{69}$ The same authors project that if the drug were to cost between $£ 3000$ and $£ 5000$ per course of treatment, the total potential cost could reach $£ 30 \mathrm{~m}$ to $£ 50 \mathrm{~m}$ annually. Clearly, funding for this agent will have to be addressed individually by the different healthcare systems in the United Kingdom and throughout Europe.
A cost effectiveness study of drotrecogin alfa (activated) as compared with conventional care for patients with severe sepsis has recently been published. Manns et al reported that drotrecogin alfa (activated) was relatively cost effective when used in patients with severe sepsis, greater severity of illness, and a reasonable life expectancy if they survive the episode of sepsis. $^{70}$

\section{CONCLUSIONS}

Drotrecogin alfa (activated), in addition to current standard therapy, has been demonstrated to be efficacious in highly selected patients with severe sepsis and septic shock but is associated with an increased risk of bleeding. Trials of drotrecogin alfa (activated) are ongoing in patients with severe sepsis who have a lower risk of death and in paediatric patients with severe sepsis. It is anticipated that additional trials will be conducted in other patient populations, including cancer patients with neutropenic sepsis and patients undergoing solid organ or haematopoietic stem cell transplantation who develop severe sepsis. The successful results with the use of drotrecogin alfa (activated) in severe sepsis has come with a better understanding of the genetic, molecular, and cellular mechanisms involved in severe sepsis. Ultimately, greater strides in human genomics and molecular biology will pave the way for more targeted treatment strategies for this highly complex and lethal syndrome.

\section{Author's affiliation}

Department of Anesthesiology and Critical Care Medicine, Memorial Sloan-Kettering Cancer Center, New York, and Weill Medical College of Cornell University, New York

\section{REFERENCES}

1 Yan SC, Razzano P, Chao YB, et al. Characterization and novel purification of recombinant human activated protein $C$ from three mammalian cell lines. Biotechnology (NY) 1990;8:655-61.

2 Anonymous. The Medical Letter on Drugs and Therapeutics 2002;44:17-8 (February 18)

3 Esmon CT. Inflammation and thrombosis: mutual regulation by protein C. Immunologist 1998;6:84-9.

4 Anti-infective Advisory Committee. FDA briefing document: drotrecogin alfa (activated) [recombinant human activated protein $C$ (rhAPC)] Xigris, BLA\# 125029/0. Rockville, MD: Food and Drug Administration 12 September 2001 laccessed 24 September 2002, at http://www.fda.gov/ohrms/dockets/ac/01/briefing/ 37ttp://www.fda.gov/ohrms/do2_FDAbriefing.doc).

5 American College of Chest Physicians/Society of Critical Care Medicine Consensus Conference. Definitions for sepsis and organ failure and guidelines for the use of innovative therapies in sepsis. Crit Care Med 1992;20:864-74

6 Bone RC, Grodzin CJ, Balk RA. Sepsis: a new hypothesis for pathogenesis of the disease process. Chest 1997;1 12:235-43.

7 Bernard GR, Vincent JL, Laterre PF, et al. Efficacy and safety of recombinant human activated protein $C$ for severe sepsis. N Engl J Med 2001;344:699-709.

8 Angus DC, Linde-Zwirble WT, Lidicker J, et al. Epidemiology of severe sepsis in the United States: analysis of incidence, outcome, and associated costs of care. Crit Care Med 2001;29:1303-10.

9 Brun-Buisson C, Doyon F, Carlet J, et al. Incidence, risk factors and outcome of severe sepsis and septic shock in adults. JAMA 1995;274:968-74

10 Sands $K$, Bates D, Lanken $P$, et al. Epidemiology of sepsis syndrome in 8 academic medical centers. JAMA 1997:278:234-40.

11 Friedman G, Silva E, Vincent JL. Has the mortality of septic shock changed with time? Crit Care Med 1998;26:2078-86.

12 Centers for Disease Control. Increase in national hospital discharge survey rates for septicemia-United States. MMWR Morb Mortal Wkly Rep 1990;39:31-4.

13 Parrillo JE. Pathogenetic mechanisms of septic shock. N Engl J Med 1993;328: 1471-7.

14 Wheeler AP, Bernard GR. Treating patients with severe sepsis. N Engl J Med 1999;340:207-14

15 Rivers E, Nguyen B, Havstad S, et al. Early goal-directed therapy in the treatment of severe sepsis and septic shock. N Engl J Med 2001;345:1368-77

16 Opal SM, Cross AS. Clinical trials for severe sepsis: past failures, and future hopes. Infect Dis Clin North Am 1999;13:285-97.

17 Freeman B, Natanson C. Anti-inflammatory therapies in sepsis and septic shock. Expert Opinion on Investigational Drugs 2000;9:1651-63. 
18 Natanson C, Esposito C, Banks S. The siren's song of confirmatory sepsis trials: selection bias and sampling errors. Crit Care Med 1998;26:1927-31.

19 Freeman BD, Buchman TG. Coagulation inhibitors in the treatment of sepsis. Expert Opinion on Investigational Drugs 2002;1 1:69-74

20 Matthay M. Severe sepsis - a new treatment with both anticoagulant and antiinflammatory properties [editorial]. N Engl J Med 2001;344:75962.

21 lba T, Kidokoro A, Yagi Y. The role of the endothelium in changes in procoagulant activity in sepsis. J Am Coll Surg 1998;187:321-9.

22 Bernard GR, Ely EW, Wright TJ, et al. Safety and dose relationship of recombinant human activated protein $C$ for coagulopathy in severe sepsis. Crit Care Med 2001;29:2051-9

23 Warren BL, Eid A, Singer P, et al. High-dose antithrombin III in severe sepsis: a randomized controlled trial. JAMA 2001;286:1869-78.

24 Abraham E. Tissue factor inhibition and clinical trial results of tissue factor pathway inhibitor in sepsis. Crit Care Med 2000;28/suppl 9): $531-533$

25 Corrigan JJ, Ray WL, May N: Changes in the blood coagulation system associated with septicemia. N Engl J Med 1968;279:851-6.

26 Hinshaw LB. Sepsis/septic shock: participation of the microcirculation: an abbreviated review. Crit Care Med 1996:24:1072-8.

27 Parent C, Eichacker PQ. Neutrophil and endothelial cell interactions in sepsis: the role of adhesion molecules. Infect Dis North Am $1999 ; 13: 427-47$

28 Levi $M$, ten Cate $H$. Disseminated intravascular coagulation. N EnglJ Med 1999;341:586-92.

29 Osterud B, Flaegstad T. Increased tissue thromboplastin activity in monocytes of patients with meningococcal infection: related to an unfavorable prognosis. Thromb Haemost 1983;49:5-7.

30 Taylor FB Jr, Chang A, Ruf W, et al. Lethal E coli septic shock is prevented by blocking tissue factor with monoclonal antibody. Circ Shock $1991 ; 33: 127-34$

31 van der Poll T, Buller HR, ten Cate $\mathrm{H}$, et al. Activation of coagulation after administration of tumor necrosis factor to normal subjects. N Engl J Med 1990:322:1622-7.

32 van Deventer SJH, Bluller HR, ten Cate JW, et al. Experimental endotoxemia in humans: an analysis of cytokine release and coagulation fibrinolytic and complement pathways. Blood 1990;76:2520-8.

33 Dickneite G. Antithrombin III in animal models of sepsis and organ failure. Semin Thromb Haemost 1998:24:61-9.

34 Vervolet MG, Thiis LG, Hack CE. Derangements of coagulation and fibrinolysis in critically ill patients with sepsis and septic shock. Semin Thromb Haemost 1998;24:33-44.

35 Levi $\mathbf{M}$, van der Poll T, ten Cate $H$, et al. The cytokine-mediated imbalance between coagulant and anticoagulant mechanisms in sepsis and endotoxemia. Eur J Clin Invest 1987;27:3-9.

36 Herbert JM, Dupuy E, Laplace MC, et al. Thrombin induces endothelia cell growth via both a proteolytic and a non-proteolytic pathway. Biochem J 1994:303:227-31.

37 Jones A, Geczy CL. Thrombin and factor Xa enhance the production of interleukin-1. Immunology 1990;71:236-41.

38 Cunningham MA, Romas $\mathrm{P}$, Hutchinson $\mathrm{P}$, et al. Tissue factor and factor Vlla receptor/ligand interactions induce proinflammatory effects in macrophages. Blood 1999:94:3413-20.

39 Mesters RM, Mannucci PM, Coppola R, et al. Factor Vlla and antithrombin III activity during severe sepsis and septic shock in neutropenic patients. Blood 1996;88:881-6.

40 Mesters RM, Helterbrand J, Utterback B, et al. Prognostic value of protein $C$ concentrations in neutropenic patients at high risk of severe septic complications. Crit Care Med 2000;28:2209-16.

41 Fourrier F, Chopin C, Goudemand J, et al. Septic shock, multiple organ failure and disseminated intravascular coagulation: compared patterns of antithrombin III, protein $\mathrm{C}$ and protein $\mathrm{S}$ deficiencies. Chest 1992;101:816-23

42 Lorente JA, Garcia-Frade L, Landin L, et al. Time course of hemostatic abnormalities in sepsis and its relation to outcome. Chest 1993:103:1536-42

43 Fisher CJ, Yan SB. Protein C levels as a prognostic indicator of outcome in sepsis and related diseases. Crit Care Med 2000;28(suppl):S49-S56.

44 Esmon CT, Ding W, Yasuhiro K, et al. The protein C pathway: new insights. Thromb Haemost 1997;78:70-4.
45 Comp PC, Esmon CT. Regulatory mechanisms in hemostasis: natural anticoagulants. In: Hoffman R, Benz EJ, Shattil SJ, et al, eds. Hematology: basic principles and practice. New York: Churchill Livingstone, 1991: basic prin $1243-51$

46 Joyce DE, Gelbert L, Ciaccia A, et al. Gene expression profile of antithrombotic protein $C$ defines new mechanisms modulating inflammation and apoptosis. J Biol Chem 2001;276:1 11 199-203.

47 Grinnell BW, Joyce D. Recombinant human activated protein C: a system modulator of vascular function for treatment of severe sepsis. Crit Care Med 2001;29(suppl):S53-S61.

48 Deveraux QL, Reed JC. IAP family proteins: suppressors of apoptosis. Genes Dev 1999;13:239-52.

49 Faust SN, Levin $M$, Harrison OB, et al. Dysfunction of endothelial protein $C$ activation in severe meningococcal sepsis. N Engl J Med 2001;345:408-16.

50 Fijnvandraat K, Derkx B, Peters $M$, et al. Coagulation activation and tissue necrosis in meningococcal septic shock: severely reduced protein $\mathrm{C}$ levels predict a high mortality. Thromb Haemost 1995;73:15-20.

51 Taylor FB, Chank A, Esmon CT, et al. Protein C prevents the coagulopathic and lethal effects of $\mathrm{E}$ coli infusion in the baboon. J Clin Invest 1987;79:918-25

52 Ettingshausen CE, Veldmann A, Beeg T, et al. Replacement therapy with protein $C$ concentrate in infants and adolescents with meningococcal sepsis and purpura fulminans. Semin Thromb Hemost 1999;25:537-41.

53 Rintala $E$, Seppala OP, Kotilainen $P$, et al. Protein $C$ in the treatment of coagulopathy in meningococcal disease. Crit Care Med 1998:26:965-8.

54 Smith OP, White B, Vaughan D, et al. Use of protein-C concentrate heparin, and haemodiafiltration in meningococcus-induced purpura fulminans. Lancet 1997;350:1590-3.

55 Dreyfus M, Magny JF, Bridey F, et al. Treatment of homozygous protein $C$ deficiency and neonatal purpura fulminans with a purified protein $C$ concentrate. N Engl J Med 1991;325:1565-8.

56 Gerson WT, Dickerman JD, Bovill EG, et al. Severe acquired protein C deficiency in purpura fulminans associated with disseminated intravascular coagulation: treatment with protein $C$ concentrate. Pediatrics 1993;91:418-22.

57 White B, Livingston W, Murphy C, et al. An open-label study of the role of adjuvant hemostatic support with protein $C$ replacement therapy in purpura fulminans-associated meningococcemia. Blood 2000;96:3719-24

58 Alberio L, Lammle B, Esmon CT. Protein C replacement in severe meningococcemia: rationale and clinical experience. Clin Infect Dis 2001:32:1338-46

59 Ehrlich HJ, Jaskunas SR, Grinnell BW, et al. Direct expression of recombinant activated human protein $\mathrm{C}$, a serine protease. J Biol Chem 1989:25:264: 14298-304

60 Eli Lilly. Xigris (drotrecogin alfa [activated]). Product information. Indianapolis: Eli Lilly, November 2001

61 Knaus WA, Draper EA, Wagner DP, et al. APACHE II: a severity of disease classification system. Crit Care Med 1985;13:818-29.

62 Bernard GR, Ely EW. Letter to the editor. N Engl J Med 2001;345:219-21.

63 Ely EW, Bernard GR. Letter to the editor. N Engl J Med 2002;347:1035-6.

64 Gordon B, Haire W, Ruby E, et al. Prolonged deficiency of protein C following hematopoietic stem cell transplantation. Bone Marrow Transplant 1996;17:415-9.

65 Haire WD, Ruby El, Gordon BG, et al. Multiple organ dysfunction syndrome in bone marrow transplantation. JAMA 1995;274:1289-95.

66 Annane D, Sebille V, Charpentier C, et al. Effect of treatment with low doses of hydrocortisone and fludrocortisone on mortality in patients with septic shock. JAMA 2002;288:862-71.

67 Healy DP. New and emerging therapies for sepsis. Ann Pharmacother 2002;36:648-54

68 Anonymous. Drug topics red book (update). Montvale, NJ: Medica Economics, January 2002

69 Padkin A, Rowan K, Black N. Using high quality clinical databases to complement the results of randomised controlled trials: the case of recombinant human activated protein C. BM 2001;323:923-26.

70 Manns B, Lee H, Doig CJ, et al. An economic evaluation of activated protein C treatment for severe sepsis. N Engl J Med 2002;347:9931000 . 